\title{
Seismic behaviour of soft clay and its influence on the response of friction pile foundations
}

\author{
Thejesh Kumar Garala ${ }^{1}$ · Gopal S. P. Madabhushi ${ }^{2}$
}

Received: 6 June 2018 / Accepted: 27 October 2018 / Published online: 8 November 2018 (C) The Author(s) 2018

\begin{abstract}
In recent years, much of the research in geotechnical earthquake engineering has focused on liquefaction of loose, saturated sands and silts. However, the dynamic behaviour of soft, clayey soils and their interaction with pile foundations during the earthquakes have received relatively little attention. In this study, an attempt is made to investigate the dynamic behaviour of soft clay and its interaction with pile foundations during earthquakes using high gravity centrifuge testing. A model single pile and two sets of $3 \times 1$ row model pile groups with different pile spacing were embedded in soft kaolin clay and tested under the action of model earthquakes at 50 times the earth's gravity. The strength and stiffness of clay were evaluated using a T-bar test and an air hammer device respectively. The focus of this research is to investigate the dynamic response of friction piles in soft clay. However, this depends on the dynamic response of the soft clay layer around the pile. To this end, one-dimensional ground response analysis was performed using DEEPSOIL software to emphasise the importance of non-linear analysis in characterising the seismic behaviour of soft clays. It will be shown that clay response depends both on the earthquake intensity and the shear strength and stiffness of the clay layer. This has a direct bearing on the response of single piles and pile groups, with larger amplification occurring for small intensity earthquakes and attenuation occurring for stronger earthquakes.
\end{abstract}

Keywords Centrifuge $\cdot$ Earthquakes $\cdot$ Pile group $\cdot$ Single pile $\cdot$ Soft clay

\section{Problem definition and background}

Fine-grained soils with high moisture content and low shear strength are characterised as soft soils and are usually considered as challenging for the design of geotechnical structures. Such soft soils are widely spread along the coastal lines of many seismic regions like Indonesia, Philippines, Mexico, India, and China. Large and differential settlements are the typical problems usually observed in the structures constructed over soft soils. Moreover, during the earthquakes, soft soils can amplify the seismic motion and can significantly

Thejesh Kumar Garala

tkg24@cam.ac.uk

1 Schofield Centre, Department of Engineering, University of Cambridge, Cambridge CB3 0EL, UK

2 Department of Engineering, University of Cambridge, Cambridge CB2 1PZ, UK 
influence the amplitude, frequency and duration of ground motion that reaches the foundations and hence the subsequent dynamic response of the superstructure.

In such problematic soft soils, pile foundations are widely used on land and offshore to transfer heavy superstructure loads to deep layers of soil, relying on skin-friction and end-bearing. Further, pile foundations are considered as a solution to control the total and differential settlement of structures constructed over soft soils (Hansbo 1984; Horikoshi and Randolph 1996). In earthquake-prone areas, along with the static loads from the superstructure, these pile foundations are subjected to additional dynamic loads from the surrounding soil during seismic events. If they are not designed to resist these additional loads, pile foundations can fail. Therefore, the response of pile foundations and surrounding soil during earthquakes should be well understood for the safe design of deep foundations and the superstructures they support.

Some analytical and numerical solutions have been developed since after 1964 Niigata and Alaskan earthquakes for understanding the behaviour of pile foundations during earthquakes (Agarwal 1973; Novak 1974; Gazetas 1984; Mamoon and Banerjee 1990; Fan et al. 1991; Anoyatis et al. 2013). However, most of these studies are focussed on dynamic pile foundation behaviour in cohesionless soils.

Further, experiments using shaking table at normal gravity $(1 \mathrm{~g})$ are widely adopted by several researchers (Mizuno et al. 1984; Mizuno and Iiba 1992; Finn and Gohl 1992; Sreerama 1993; Meymand 1998; Hokmabadi 2014; Durante et al. 2016) to study the dynamic behaviour of piles because of the simplicity in testing. It is now well-established that 1-g shaking table tests do not simulate field stress-strain conditions in a small-scale model. The stress-strain similarity between model and prototype can be obtained by subjecting the models to enhanced gravity field using a centrifuge. More details about centrifuge testing are discussed in later sections. A reasonable number of centrifuge studies have been carried out to investigate the behaviour of pile foundations in dry and saturated sands for both level and inclined ground conditions (Madabhushi et al. 2010). However, a very limited amount of experimental data is available on the dynamic behaviour of pile foundations in soft clay. The few centrifuge experimental studies on clays with pile foundations (Rashidi 1994; Wilson 1998; Banerjee 2009; Zhang et al. 2017) are all for end-bearing pile foundations, in which most of them observed amplification in pile foundations and clay response for the different intensities of shaking. In contrast, Idriss (1990) predicts significant amplification in soft clays for low to medium bedrock accelerations up to $0.3 \mathrm{~g}$ and attenuation for stronger bedrock accelerations, based on equivalent linear analyses. Also, the recent study of Zhou et al. (2017) on deep offshore clay deposits confirm the attenuation of accelerations during large earthquakes due to the soil nonlinearity and local shear failure. Therefore, there is a scarcity of good quality research that explains the behaviour of friction pile foundations before and after the yielding of clay during strong earthquakes.

In the present study, centrifuge experiments have been carried out to study the dynamic behaviour of friction pile foundations in such soft clays where one can expect the local yielding of clay during the strong earthquakes. It is acknowledged that the use of friction pile foundations in soft clay is less common in practice due to their limited axial capacity. However, this experimental data can be used to validate existing analytical models or propose new ones to simulate the behaviour of friction pile foundations in soft clay under seismic action. In this study, model pile foundations made from aluminium tubes were used to fabricate a single pile and two sets of $3 \times 1$ row model pile groups with different pile spacing and were embedded into the soft kaolin clay. The strength and stiffness of clay were evaluated using the T-bar test (Lau 2015) and air hammer device (Ghosh and Madabhushi 2002) respectively. This paper first discusses the influence of intensity of sinusoidal 
excitations on clay behaviour based on the observations from the centrifuge data. Further, one-dimensional (1-D) ground response analysis using DEEPSOIL (Hashash et al. 2017) was performed to highlight the differences between equivalent linear and non-linear analyses for the soft soil sites. Later, the behaviour of single pile and pile groups during the small and strong intensity sinusoidal excitations are discussed based on the results obtained from the centrifuge testing. The following section explains the experimental procedure adopted in this study.

\section{Experimental procedure}

\subsection{Physical modelling using the centrifuge}

Centrifuge modelling facilitates simulation of the field stress-strain conditions in a scaled-down model of a geotechnical structure. The scaled-down models are subjected to increased g-field with the help of a large geotechnical centrifuge to achieve stress-strain similarity in model and prototype. Convenient scaling, ease of data monitoring, repeatability, controlled conditions and smaller costs make centrifuge modelling preferable over full-scale field tests. The principle, mechanics, scaling laws, various types of centrifuge, advantages and disadvantages of centrifuge modelling are well covered in Schofield (1980) and Madabhushi (2014).

In this research, the Turner beam centrifuge (Schofield 1980) at Schofield Centre, University of Cambridge, was used to test the scaled centrifuge models. Stored angular momentum (SAM) actuator developed by Madabhushi et al. (1998) was used to fire the sinusoidal excitations of required strength. Equivalent shear beam (ESB) box (Brennan and Madabhushi 2002) was used as a container to prepare the model.

\subsection{Materials, equipment and model construction}

\subsubsection{Clay}

Laboratory grade speswhite kaolin clay was used to prepare the clay slurry. Kaolin has been widely used in many experimental campaigns in Cambridge (Lau 2015). This artificial clay helps to keep the clay mineralogy constant between the tests and thus eases the repeatability of tests. The properties of speswhite kaolin clay (Lau 2015) are given in Table 1.

\subsubsection{Model pile foundations}

An aluminium tubular model pile of length $(l) 210 \mathrm{~mm}$, diameter $(d) 15 \mathrm{~mm}$ and thickness (t) $1 \mathrm{~mm}$ was used in this study to fabricate a single pile and two $3 \times 1$ row pile group configurations with different pile spacing ( $2.67 d$ and $5.33 d$ centre-to-centre). The main intention behind these pile groups is to have a pile group with significant interaction between the piles (with pile spacing of $2.67 d$ ) and the other pile group with very little interaction (with pile spacing of $5.33 d$ ) during the earthquakes. Hereafter, the closely spaced pile group will be referred as pile group- 1 and widely spaced pile group as pile group- 2 . The surface of all the model piles was smooth, and the pile heads were attached to a pile cap as seen in Fig. 1. The dimensions shown in Fig. 1 are at model scale, and the values within 
Table 1 Properties of speswhite kaolin clay (Lau 2015)

\begin{tabular}{ll}
\hline Property & Value \\
\hline Plastic limit, PL (\%) & 30 \\
Liquid limit, LL (\%) & 63 \\
Plasticity Index, PI (\%) & 33 \\
Specific gravity, $\mathrm{G}_{\mathrm{s}}$ & 2.60 \\
Slope of critical state line (CSL) in q'-p plane & 0.90 \\
Slope of an unload-reload line, $(\kappa)$ & 0.039 \\
Intercept of CSL at $\mathrm{p}^{\prime}=1 \mathrm{kPa}(\Gamma)$ & 3.31 \\
Slope of normal consolidation line $(\lambda)$ & 0.22 \\
\hline
\end{tabular}

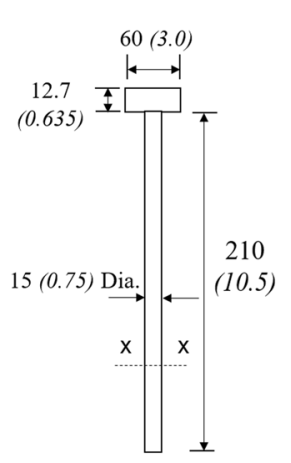

$\underline{\text { Sectional view }}$

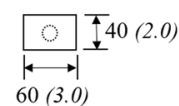

$\underline{\text { Plan view }}$

(a)

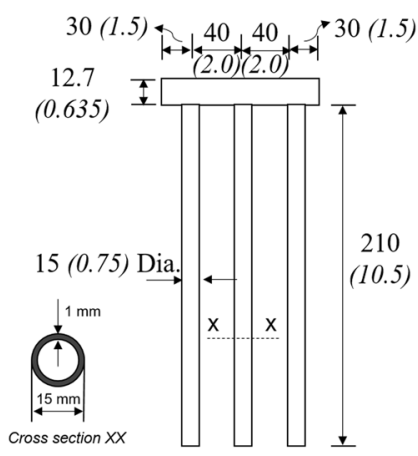

$\underline{\text { Sectional view }}$

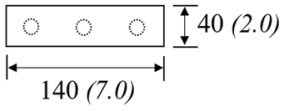

Plan view

(b)

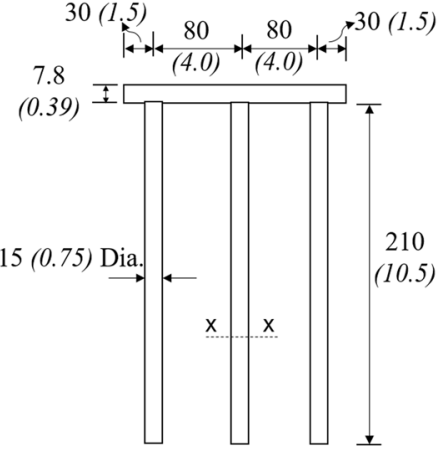

$\underline{\text { Sectional view }}$

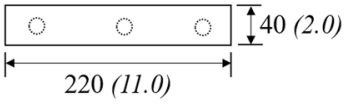

Plan view

(c)

*Model and prototype dimensions are in ' $\mathrm{mm}$ ' and ' $m$ ' respectively

Fig. 1 Pile foundations used in the study, a single pile, $\mathbf{b}$ pile group-1, $\mathbf{c}$ pile group-2

the parentheses represent the prototype dimensions. The flexural stiffness of the prototype single pile is equivalent to a $0.75 \mathrm{~m}$ diameter high strength concrete pile. Pile groups- 1 and 2 carry the same mass per pile from the pile cap, irrespective of pile spacing, and slightly less than the mass carried by the single pile. In terms of force, single pile and pile groups carry a vertical load of $41.5 \mathrm{~N}$ and $87.5 \mathrm{~N}$ respectively at model scale and $103.75 \mathrm{kN}$ and $218.75 \mathrm{kN}$ respectively at prototype scale.

\subsubsection{Model preparation}

Clay slurry was prepared by mixing the speswhite kaolin clay powder and de-aired water in 1:1.25 ratio under the vacuum. The prepared clay slurry was filled into the ESB box to 
the required depth. To obtain a more realistic soft clay profile (with a given strength at the surface and then increasing strength with depth), a combination of consolidation under vertical stress and hydraulic consolidation by suction-induced seepage (HCSS) were used to consolidate the clay slurry. Schematic view of the consolidation process adopted in this study is shown in Fig. 2. The working principle of HCSS along with a discussion on its validity was reported earlier by Robinson et al. (2003). The ESB box with clay slurry was placed under a computer-controlled hydraulic press to consolidate under vertical stress. Once the clay was consolidated under the applied vertical stress, the sample was further consolidated using HCSS method. The vertical stress and suction for HCSS method were applied combinedly aiming an average undrained shear strength of around $5 \mathrm{kPa}$.

The depth $(H)$ and density $(\rho)$ of the clay after consolidation and trimming for the levelled surface were $220 \mathrm{~mm}$ and $1623 \mathrm{~kg} / \mathrm{m}^{3}$, respectively. Piezo-electric accelerometers (P) and micro-electro-mechanical systems (MEMS) accelerometers were used to measure the accelerations in clay and pile foundations respectively. Linear variable differential transformers (LVDTs) were used to measure the settlement of clay and pile foundations at various stages of the test. Thin polytetrafluoroethylene (PTFE) stands were used to hold the piezo-electric accelerometers in the clay model at required depth and in the proper orientation. Small openings were facilitated in the PTFE stand at required depths along the stand and the piezo-electric accelerometers were placed in these openings. Vertical holes were drilled at the required locations in the consolidated clay model for the insertion of PTFE stands with piezo-electric accelerometers. The PTFE stands with the piezo-electric accelerometers were placed in these drilled holes with the least stiffness side of the PTFE stand placing in the direction of shaking. These drilled holes were later filled with partially consolidated kaolin slurry and the suction in the clay further consolidates the filled slurry. Recordings from the piezo-electric accelerometers placed on their own within the clay model at deeper depths (placed in the model before pouring the clay slurry) and at surface (placed after the clay consolidation) are consistent with the readings recorded by the piezo-electric accelerometers attached to the PTFE stand at similar depths indicating there is no interference of PTFE stand in piezo-electric accelerometers' functionality during the earthquakes. MEMS accelerometers were directly glued on to the pile caps of both single pile and pile groups. Figure 3 shows the plan view of the model and Fig. 4 shows the cross-section of the model in which the location of the instruments can also be seen. The dimensions in Figs. 3 and 4

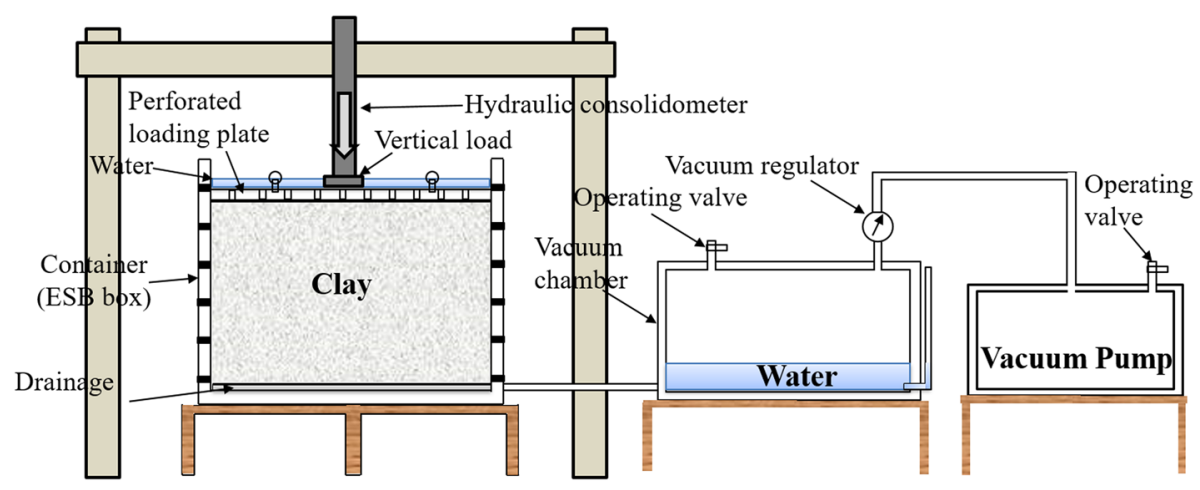

Fig. 2 Schematic view of the setup used for clay consolidation 


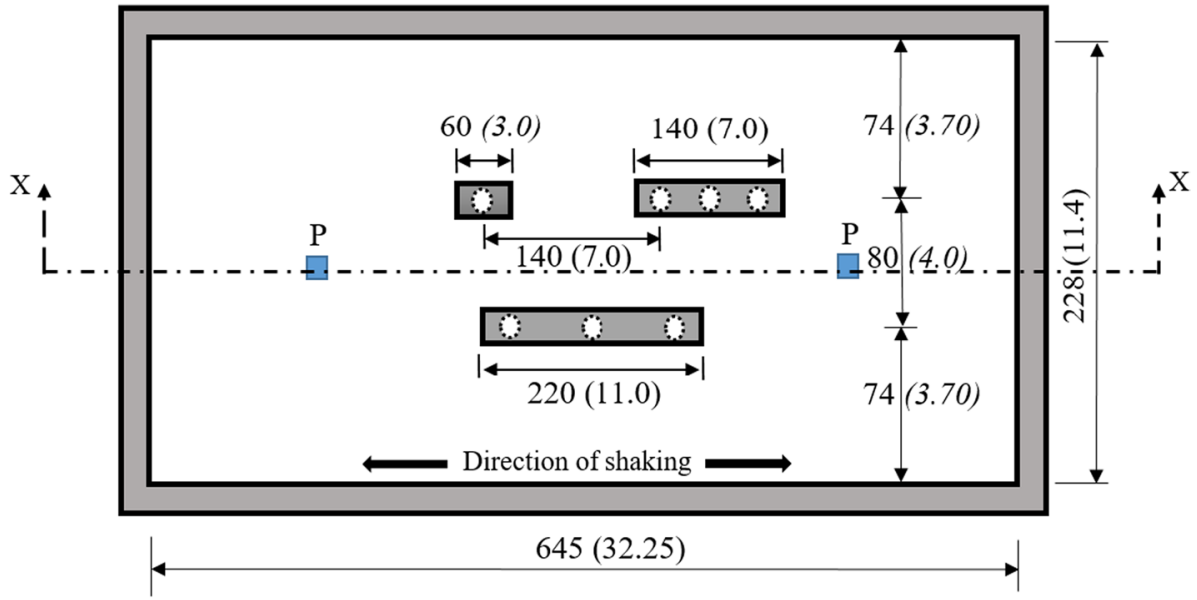

* Model and prototype dimensions are in ' $m m$ ' and ' $m$ ' respectively

Fig. 3 Plan view of the centrifuge model (not to scale)

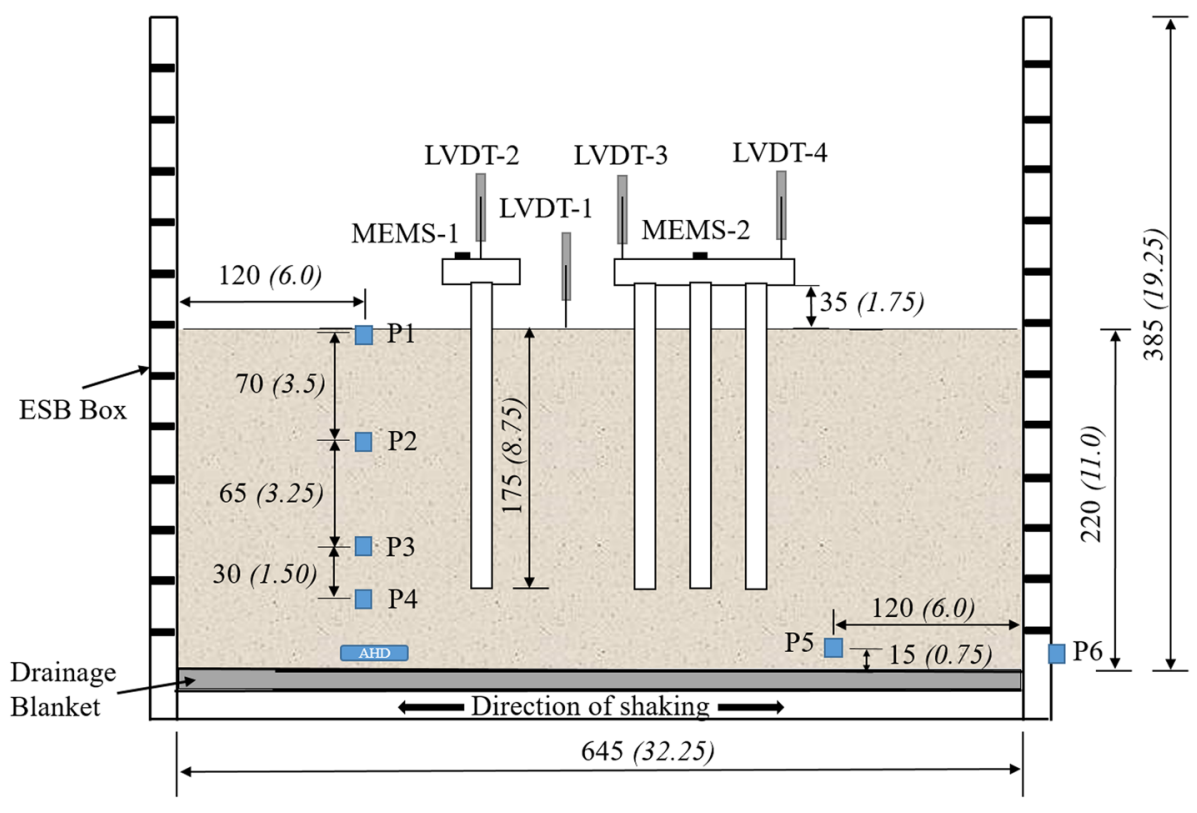

*Model and prototype dimensions are in ' $\mathrm{mm}$ ' and ' $m$ ' respectively

Fig. 4 Cross-section along the plane $X-X$ (not to scale)

are at model scale, and the values within the parentheses represent the prototype dimensions. Recordings from only a few instruments have been discussed in this article and only those are shown in Figs. 3 and 4. More details about the complete instrumentation and model preparation for similar tests can be found in Garala (2016). 
Piles were installed manually at an approximate rate of $5-8 \mathrm{~mm} / \mathrm{s}$ with intermittent stops to check for the verticality of the pile. Single pile was installed first followed by the installation of pile group- 1 and pile group- 2 respectively. Though the single pile and pile group-1 were sited on the same vertical plane in the direction of shaking, the clear gap of $8.33 d$ between them should minimise any dynamic interaction between the two. Also, the response from piezo accelerometers in the clay model can be considered as free-field clay response as the accelerometers were located reasonably far from the pile foundations and in a different vertical plane as shown in Fig. 3.

\subsubsection{Centrifuge testing and input motions}

The model was swung up to $50 \mathrm{~g}$ in increments of $10 \mathrm{~g}$ with a closed bottom drain in the centrifuge. It is worthy to mention that the consolidated clay sample will be under suction after unloading from the hydraulic press. When the clay sample is in the centrifuge, these suction pressures reduce due to an increase in the body forces and hence large effective stresses. No water was allowed to flow into the model after unloading the soil sample from the hydraulic press, even in the centrifuge. This procedure was adopted to obtain a relatively soft clay profile with depth. Once the clay model attains equilibrium, the following planned sinusoidal excitations (hereafter called as input motions) were fired using the SAM actuator (see Table 2). The reason behind the selection of these input motions is to subject the model to a variety of shaking intensities ranging from smaller to stronger magnitudes. The important research outcomes from this series of centrifuge experiments are discussed in the following sections.

\section{Seismic behaviour of clay}

\subsection{Strength and stiffness of model clay layers}

The strength of the consolidated clay was determined using a T-bar test (Lau 2015) at normal gravity ( $1 \mathrm{~g})$ immediately after unloading the model from the hydraulic press and after the centrifuge test. Figure 5a shows the undrained shear strength of clay $\left(c_{u}\right)$ determined from the T-bar before and after the centrifuge test along with the desired strength profile. In Fig. 5a, the depth axis is shown in prototype units for the better understanding of the results in later sections even though the T-bar tests were performed at $1 \mathrm{~g}$. The small humps at $1.7 \mathrm{~m}$ (before the test) and at $1.4 \mathrm{~m}$ (after the test) are because of disturbance to the T-bar driving actuator. It can be observed from Fig. 5a that the $c_{u}$ of clay before the centrifuge test is increasing with depth, indicating the success of HCSS consolidation. Also, there is a small increase in $c_{u}$ in the top half of the clay model after the test because of the reconsolidation of clay in the

Table 2 Sinusoidal excitations considered in the study (at prototype scale)

\begin{tabular}{lll}
\hline Excitation & Frequency $(\mathrm{Hz})$ & $\begin{array}{l}\text { Peak base } \\
\text { acceleration } \\
(\mathrm{g})\end{array}$ \\
\hline Input motion-1 & 0.6 & 0.07 \\
Input motion-2 & 0.8 & 0.10 \\
Input motion-3 & 1.2 & 0.22 \\
\hline
\end{tabular}


Fig. 5 a Undrained shear strength of clay (measured at $1 \mathrm{~g})$, b shear wave velocity of clay at $50 \mathrm{~g}$

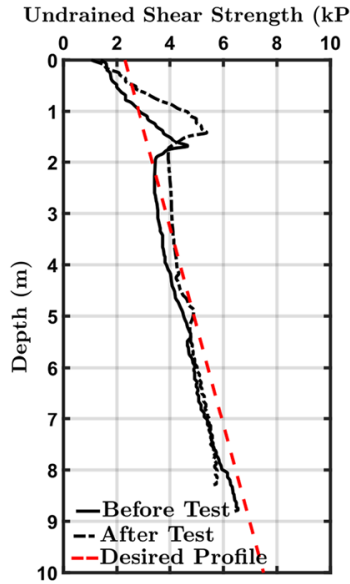

(a)

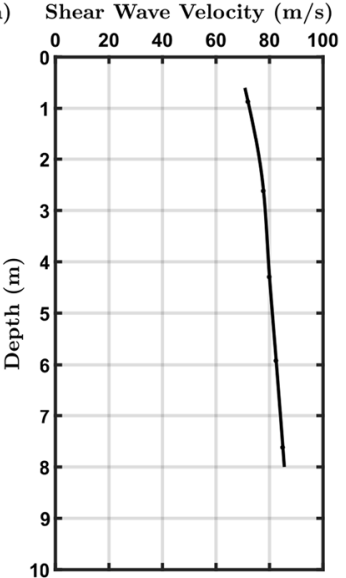

(b)

centrifuge at $50 \mathrm{~g}$. Therefore, $c_{u}$ of the clay before the earthquakes is slightly greater than the clay strength reported at $1 \mathrm{~g}$ before the test. Further, the stiffness of the clay was determined after the reconsolidation of clay at $50 \mathrm{~g}$ in the centrifuge using the air hammer device (Ghosh and Madabhushi 2002). Figure 5b shows the variation of the shear wave velocity $\left(v_{s}\right)$ with the depth of the clay. For calculating the natural frequency, an average $v_{s}$ of $\sim 80 \mathrm{~m} / \mathrm{s}$ is considered (close to $4.5 \mathrm{~m}$ depth).

Natural frequency $(f)$ of clay can be computed from $f=\frac{v_{s}}{4 H}$, where $H$ is the depth of the clay layer $(11 \mathrm{~m})$, which gives $1.82 \mathrm{~Hz}$ as the natural frequency of the clay layer.

\subsection{Dynamic response of clay layers}

The dynamic response of clay layers (and pile foundations) are presented at prototype scale, except where stated. Figure 6 shows the acceleration and corresponding fast Fourier transform (FFT) at different depths in the clay during the input motion-1. In addition to the driving frequency $(0.6 \mathrm{~Hz})$, harmonics of the driving frequency were also present in the input motion as shown in the FFT of the input motion (see Fig. 6). As the input motion propagates through the soft clay, the harmonics near the natural frequency of the clay $(1.82 \mathrm{~Hz})$ got amplified as shown in Fig. 6. As the driving frequency is far from the natural frequency, no considerable amplification was observed in the clay at the driving frequency. Similar behaviour was observed even during the input motion-2, for which the driving frequency and peak base acceleration were $0.8 \mathrm{~Hz}$ and $0.10 \mathrm{~g}$ respectively.

Figure 7 shows the acceleration recorded during the stronger intensity input motion-3 (driving frequency of $1.2 \mathrm{~Hz}$ ) along a vertical profile of piezo accelerometers. Similar to the previous case, the harmonics at $2.4 \mathrm{~Hz}$ and $3.6 \mathrm{~Hz}$ of the input motion were amplified up to $8.25 \mathrm{~m}$ and attenuating at shallower depths. Also, the driving frequency was attenuating at shallower depths where the clay $c_{\mathrm{u}}$ is smaller (see Fig. 5a). Therefore, it can be inferred from the Fig. 7 that the shear stresses induced by this relatively strong input motion are approaching the limiting $c_{\mathrm{u}}$ between 6.75 and $8.25 \mathrm{~m}$.

Shear stress $(\tau)$ generated because of acceleration signal propagation at a depth of 8.25 m during input motion-3 can be computed using Eq. (1) as: 

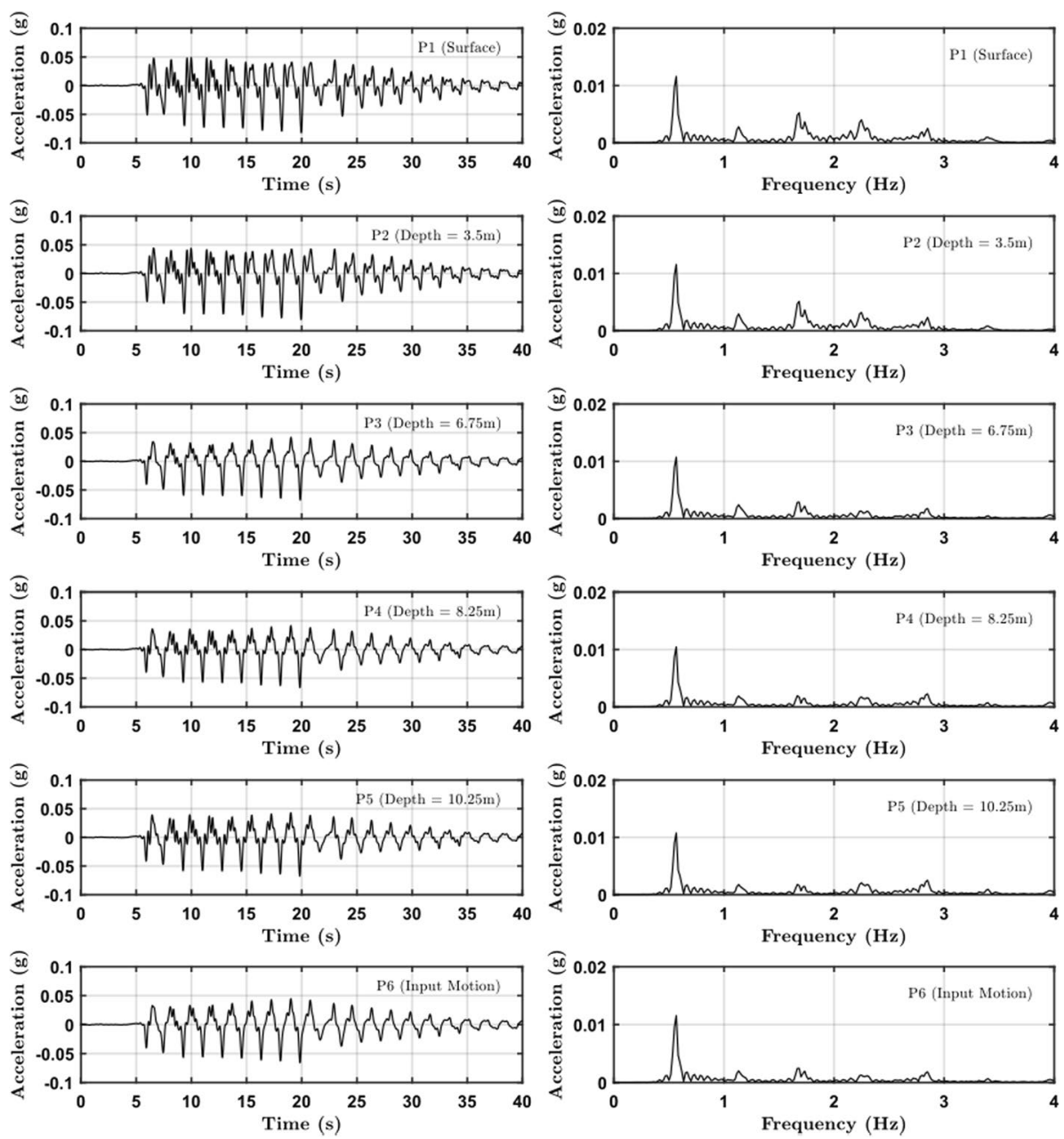

Fig. 6 Propagation of input motion-1 along the soft clay

$$
\tau=G \gamma=\rho v_{s}^{2} \frac{G}{G_{0}} \gamma
$$

where $\rho$ is the mass density, $v_{s}$ is the shear wave velocity, $\frac{G}{G_{0}}$ is the normalised shear modulus value ( $G$ is the shear modulus at any given point and $G_{0}$ is the maximum shear modulus) at a strain of $\gamma$.

$\frac{G}{G_{0}}$ and $\gamma$ for input motion-3 at a depth of $8.25 \mathrm{~m}$ are determined using Brennan et al. (2005) and shown in Fig. 8a. More details regarding the modulus reduction and damping curves are covered in the later sections.

From Fig. 8a, $\frac{G}{G_{0}}=0.16$ at $\gamma=0.32 \%$ at a depth of $8.25 \mathrm{~m}$ for the peak acceleration cycle propagation during the input motion-3.

Substituting these values in Eq. (1), $\tau=1623 \times 85^{2} \times 0.16 \times 0.0032$. 

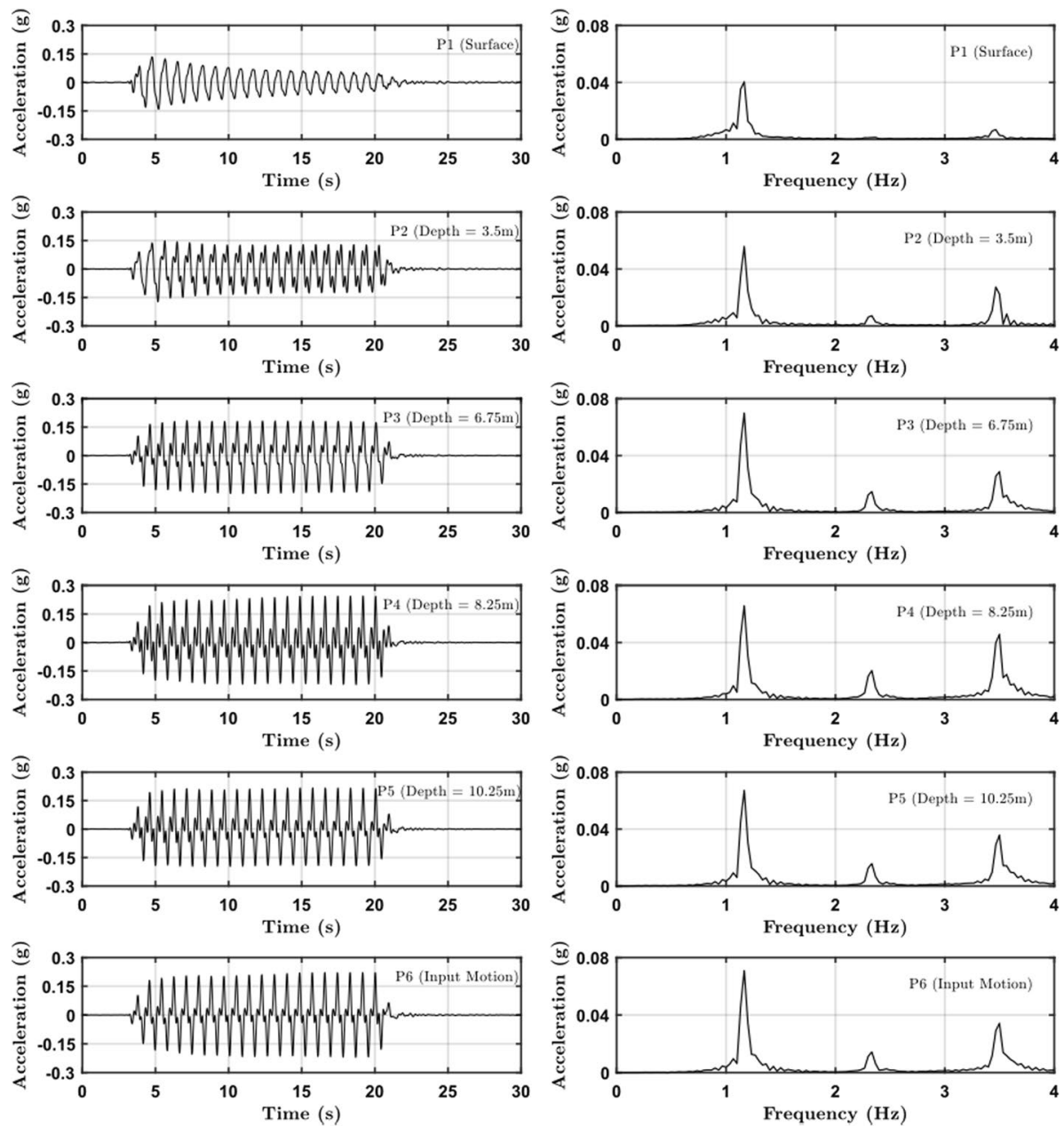

Fig. 7 Propagation of input motion-3 along the soft clay

$$
\tau \approx 6000 \mathrm{pa}=6 \mathrm{kPa}
$$

At depths shallower than $8.25 \mathrm{~m}$, accelerations may have tried to amplify further causing shear stresses to exceed $6 \mathrm{kPa}$. However, the limited values of $\mathrm{c}_{\mathrm{u}}$ within the shallower depths constrained the increase of shear stress, causing the clay to yield and limiting the accelerations.

In Fig. 7, the attenuation of accelerations at shallower depths is clearly seen. This is attributed to the inability of clay to transmit the input accelerations due to its limited shear strength. In order to investigate the stress wave propagation in a yielding soil, 1-D analyses were carried out in linear and non-linear materials as explained next. 


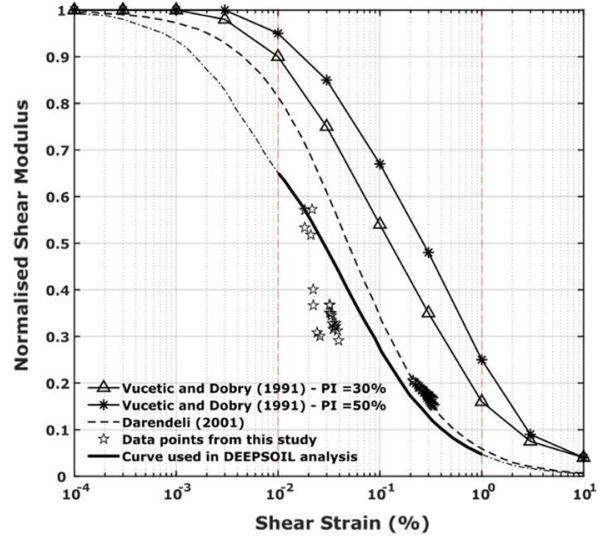

(a)

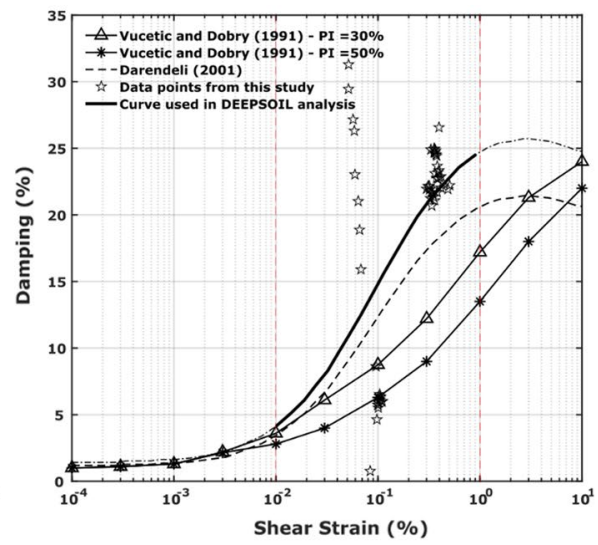

(b)

Fig. 8 a Normalised shear modulus, b damping curves used in the DEEPSOIL analysis at a depth of $8.25 \mathrm{~m}$

\subsubsection{1-D ground response analysis using DEEPSOIL}

Typical ground response analysis involves the understanding of changes in stress waves as they propagate through the soil profile from the bedrock to the surface. In 1-D ground response analysis, all layers of soil strata are assumed to be horizontal and that the response of a soil deposit is predominantly caused by vertically propagating $S_{h}$ waves from the underlying bedrock (Kramer 1996). 1-D ground response analysis can be performed by linear, equivalent linear or non-linear methods. Clearly linear and equivalent linear methods do not capture the soil yielding as there is no limit on shear strength in such analyses. Non-linear analysis carried out in the time domain can capture the limiting accelerations transmitted during a strong earthquake, such as input motion-3 explained in the previous section.

Recent studies on seismic site characterisation used 1-D linear or equivalent linear site response analysis (Phanikanth et al. 2011; Mahmood et al. 2016; and Puri et al. 2018), in which there are a few sites with soft clay deposits. To emphasise the difference between equivalent linear and non-linear seismic site response analyses for soft clays, 1-D equivalent linear and non-linear analyses were performed on a soil model that closely represents the soft clay in the centrifuge test using DEEPSOIL software (Hashash et al. 2017). The results obtained from the DEEPSOIL analyses were compared with the centrifuge data.

The $11 \mathrm{~m}$ deep soft clay was divided into a finite number of layers of small thickness in the DEEPSOIL software, and corresponding density, shear wave velocity and undrained shear strength (see Fig. 5) were assigned to each layer. Shear modulus reduction and damping ratio curves for the model clay layer were determined from the dynamic centrifuge data as explained.

\subsubsection{Shear modulus reduction and damping curves}

Shear stresses and shear strains were computed at various depths from the accelerationtime histories following Brennan et al. (2005). Shear modulus and damping ratio were determined by plotting the variation of shear stress with shear strain (hysteresis loops). 
Maximum shear modulus $\left(\mathrm{G}_{\max }\right)$ was determined from $G_{\max }=\rho v_{s}^{2}$, where $\rho$ is the density and $v_{s}$ is the shear wave velocity (see Fig. $5 \mathrm{~b}$ ).

Figure 8 shows the normalised shear modulus (ratio of shear modulus to the maximum shear modulus) and damping computed from all the shaking events in this centrifuge test at an average depth of $8.25 \mathrm{~m}$. The typical modulus reduction and damping curves available in the literature are also shown in Fig. 8. Vucetic and Dobry (1991) modulus reduction and damping curves consider the influence of PI of the clay but are independent of effective confining stresses $\left(\sigma_{0}{ }^{\prime}\right)$. Darendeli (2001), on the other hand, considers the influence of both $\sigma_{0}{ }^{\prime}$ and PI of the clay. The values obtained in this study are closer to the modulus reduction and damping curves proposed by Darendeli (2001). For this analysis, a smoothed curve has been fitted for the obtained data points within the strain range of interest $\left(10^{-2}-1 \%\right)$ to establish the modulus reduction curve to closely represent the dynamic behaviour of soft clay tested in the centrifuge. However, the damping values are widely spread across the strain values, and a smoothed curve cannot be established. It can be seen in Fig. 8a that the values on the smoothed modulus reduction curve are almost $20 \%$ less than the values of Darendeli (2001) at the same strain. Therefore, the damping values of Darendeli were increased by $20 \%$ and used as a damping reference curve in this analysis as shown in Fig. 8b. The multiple trial and error attempts using DEEPSOIL indicated that the assumed modulus reduction and damping curves represent the tested soft kaolin clay more realistically. Groholski et al. (2016) generalised quadratic/hyperbolic (GQ/H) model with shear strength control was used in this analysis. This model automatically corrects the reference curves based on the specified shear strength at the large strains (Hashash et al. 2017).

\subsubsection{DEEPSOIL analysis and comparison with centrifuge results}

The acceleration recorded by the deepest accelerometer in the clay profile during the centrifuge test was used as the base excitation for the DEEPSOIL analysis. Figure 9 shows the acceleration recorded at the surface of the clay profile for the input motion-1 from both centrifuge experiment and DEEPSOIL software. As seen in Fig. 9, all methods are predicting a slight amplification for this smaller intensity input motion-1, with the non-linear analysis matching the centrifuge data in the first few cycles slightly better. Further, there is a small mismatch in high-frequency harmonics between DEEPSOIL non-linear analysis and centrifuge data which can be observed in the FFT plots of Fig. 9.

Figure 10 shows the results of DEEPSOIL analysis and centrifuge data for the stronger intensity input motion-3. It can be seen from Fig. 10 that the non-linear DEEPSOIL analysis and centrifuge data are showing the attenuation of shear waves as they propagate through the soft clay and recorded smaller magnitudes of acceleration at the surface compared to the input motion.

However, the equivalent linear analysis predicts amplification of the seismic shear waves as they propagate through the soft clay and results erroneously in large surface accelerations. Moreover, as no stiffness degradation with the number of loading cycles is possible in such analyses, there is no change in the soil response with an increase in the number of loading cycles. In contrast, the non-linear analysis is able to capture both attenuation in peak accelerations and degradation with the number of loading cycles quite well as seen in Fig. 10. From these analyses, it can be concluded that for smaller intensity input motions, the site response analysis can be carried out using equivalent linear or non-linear techniques as confirmed by the centrifuge test data. However, for stronger intensity input 

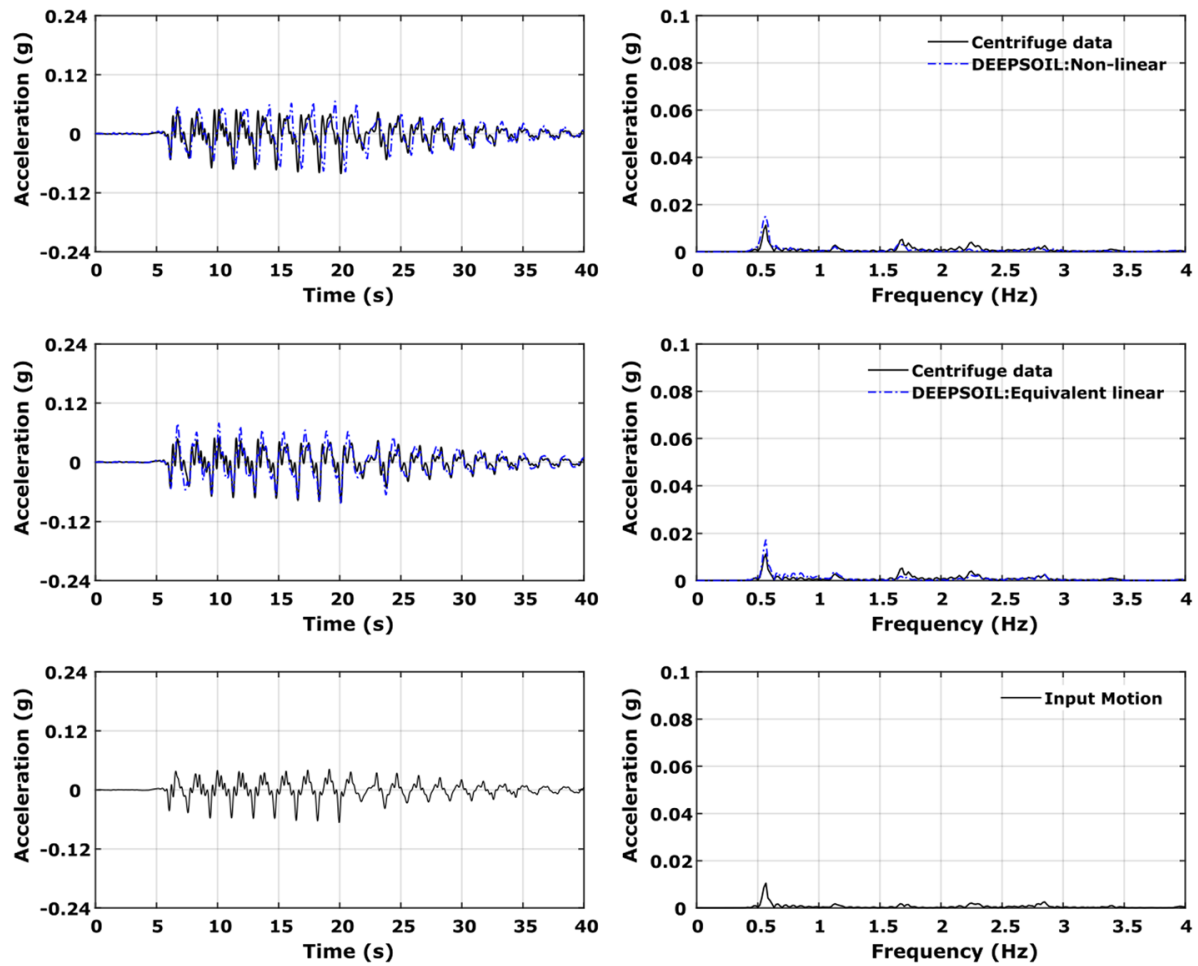

Fig. 9 Comparison of centrifuge data with DEEPSOIL analyses for input motion-1

motions, it is imperative that non-linear site response analyses are carried out and only such analyses are able to capture the observed centrifuge results. This was also observed by Zhou et al. (2017) with respect to soft, offshore clay deposits.

The transmission of stress waves from bedrock through the soft clays has implications to the seismic behaviour of pile foundations embedded in such soils. Smaller intensity input motions can be amplified through the soft clay and this can result in amplification of accelerations at the pile heads of the single pile or pile groups. Stronger intensity input motions, on the other hand, can suffer attenuation as they pass through soft clay (owing to its limited shear strength) and correspondingly the single pile or pile groups can see smaller accelerations at their pile heads. This aspect is investigated next.

\subsection{Dynamic behaviour of pile foundations}

\subsubsection{Settlement of pile foundations}

During the increase in centrifuge acceleration from 1 to $50 \mathrm{~g}$, clay surface has settled by $0.082 \mathrm{~m}$ while the single pile has settled by $0.105 \mathrm{~m}$ and pile groups- 1 and 2 have settled by $0.888 \mathrm{~m}$ and $0.096 \mathrm{~m}$ respectively. The pile group-1 (pile spacing $\sim 2.67 d$ ) has settled excessively compared to either the single pile or pile group-2 (pile spacing $\sim 53 d$ ). Furthermore, a sudden block failure was observed while increasing the centrifugal acceleration from 40 to $50 \mathrm{~g}$ in pile group-1 as seen in Fig. 11. In this figure, the settlement and 

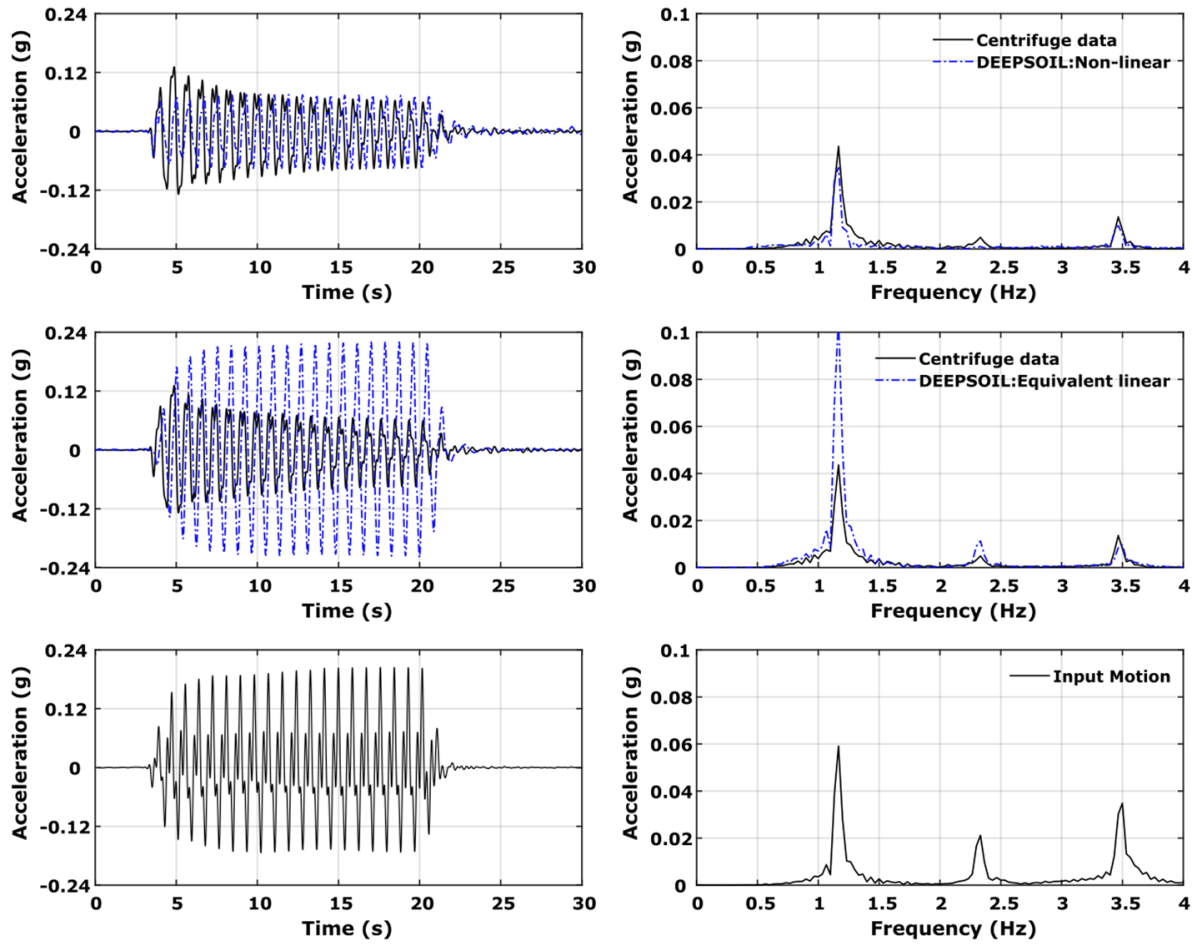

Fig. 10 Comparison of centrifuge data with DEEPSOIL analyses for input motion-3

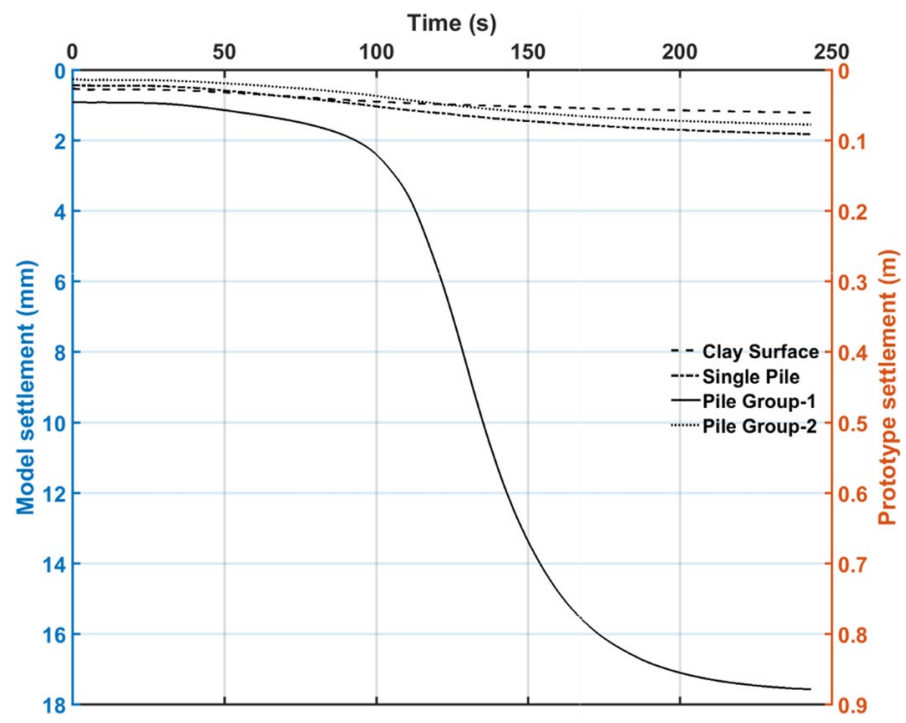

Fig. 11 Settlement recorded during swing up of the model in centrifuge from 20 to $50 \mathrm{~g}$ time axes are shown in model scale. The prototype settlements are plotted on the secondary 
axis on the right-hand side. The pile spacing of $2.67 d$ for pile group- 1 is less than the minimum $3 d$ recommended by Tomlinson (1995) for pile groups in soft clay. As the piles are closely spaced for the significant interaction between them during input motions, there may be an overlap of the zones of increased stress beneath the tip of the piles under static loading leading to a block failure and causing excessive settlement in pile group-1. In contrast, the pile group- 2 has a much larger pile spacing of $5.33 d$ and therefore no block failure occurred and consequently the settlement suffered by this pile group was small. The single pile also suffered relatively small settlement albeit being marginally larger than the pile group-2, owing to its slightly larger pile head mass (see Fig. 1). The observed settlements are in line with the expected behaviour of the single pile and pile groups-1 and 2 . They highlight the elevation of the pile tip prior to any input motion being applied, as shown in Fig. 12. A potential clay yielding zone observed during input motion-3 is also evinced in Fig. 12.

\subsubsection{Acceleration response of pile foundations}

Figure 13 shows the response of clay surface and pile foundations during the input motions-1 and 3. During the smaller intensity input motion-1, it can be seen that both the clay body and the piles show amplification. Further, the single pile and the pile groups-1 and 2 all show slightly higher amplification than the clay surface as seen in Fig. 13a. During the stronger intensity input motion-3, the clay surface shows severe attenuation as seen in Fig. 13b owing to the limited shear strength of the clay as explained in previous sections. However, the single pile and pile groups- 1 and 2 show strong amplification, particularly at the start of the input motion-3. It can be seen that the single pile shows higher amplification compared to pile groups-1 and 2. Further, pile group-2 shows higher amplification than pile group-1. This suggests that the piles in group-1 act together owing to their smaller pile spacing $(2.67 d$ ). There is some degree of attenuation of accelerations seen by

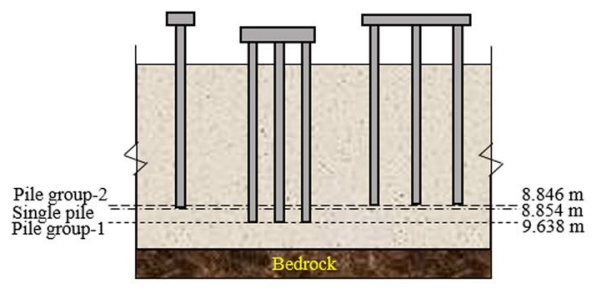

Before input motion-1

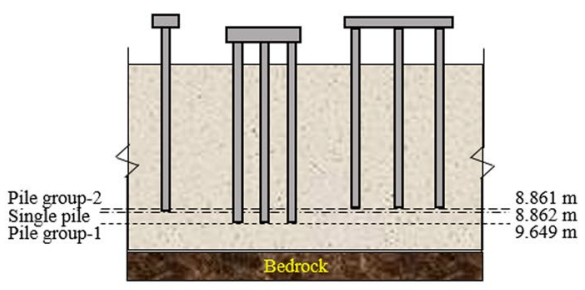

Before input motion-2

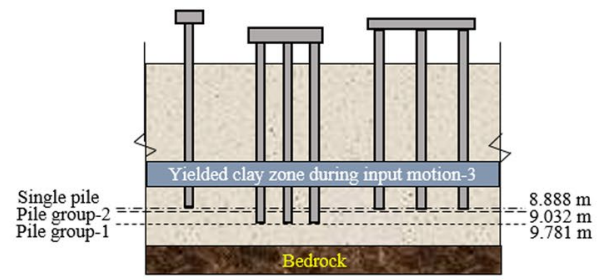

Before input motion-3

Fig. 12 Embedded depth of pile foundations before each input motion fired in the study 

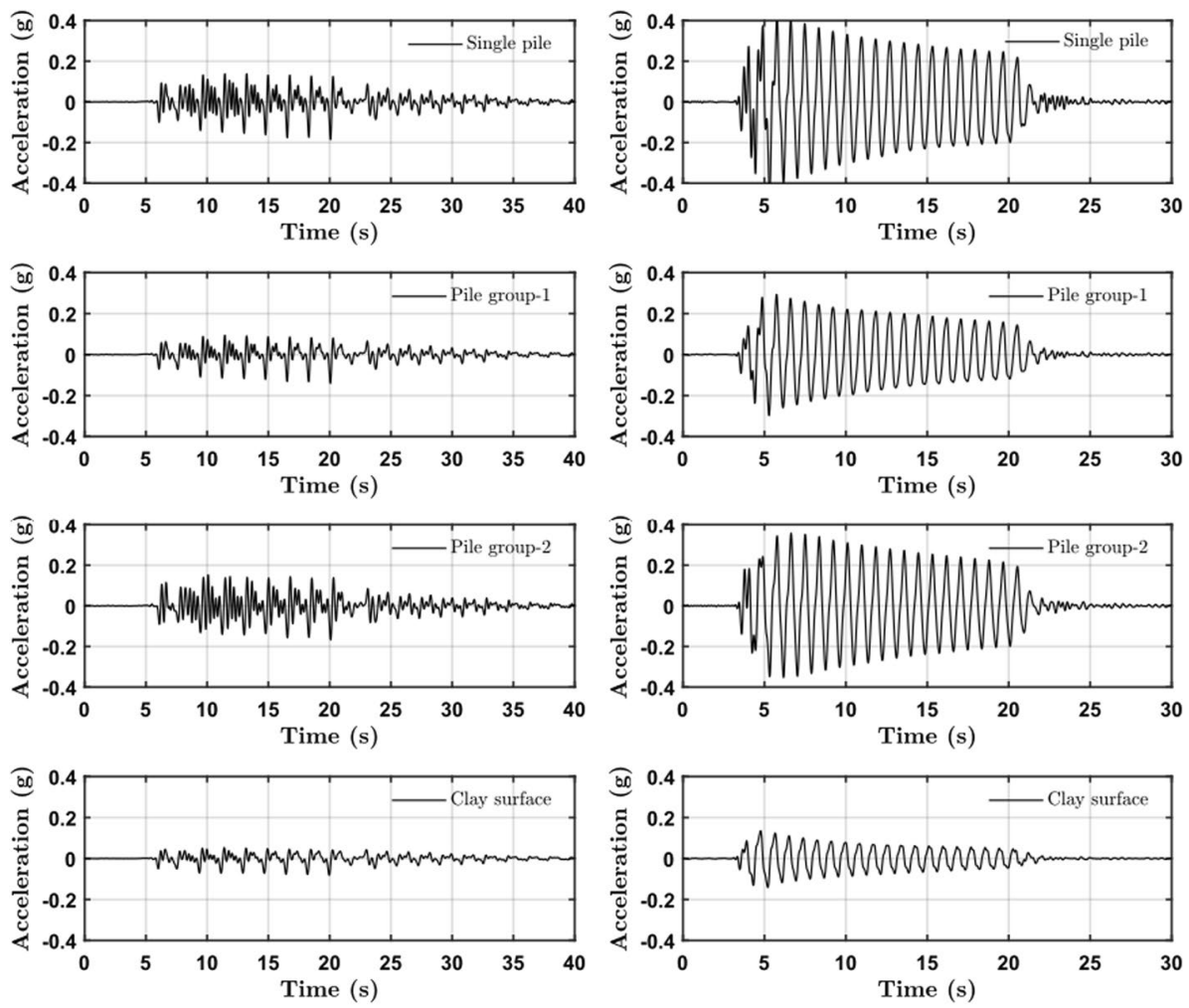

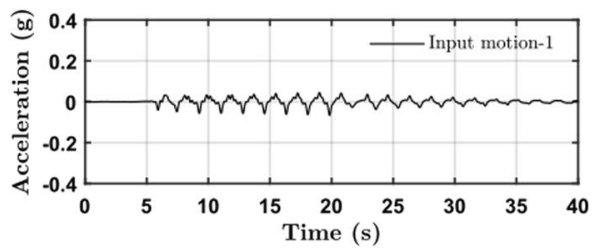

(a)

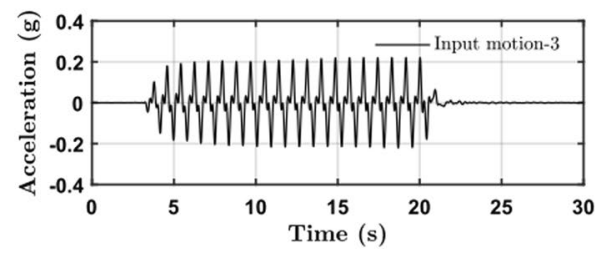

(b)

Fig. 13 Response of pile foundations during, a input motion-1, $\mathbf{b}$ input motion-3

the pile heads with number of cycles. This suggests that the tops of the piles are undergoing much larger vibrations relative to the clay surface and this must lead to a strong interaction between the piles and the surrounding clay. This is true for the single pile and the two pile groups- 1 and 2 tested.

Discussion on the behaviour of pile foundations during different input motions can be seen in terms of Arias intensity (Arias 1970). Arias intensity of a signal includes the effects of both amplitude and frequency content and is computed as a function of time using the Eq. (2). The final value of the Arias intensity, say $I_{a, \infty}$, can be determined using the Eq. (3)

$$
I_{a}(t)=\frac{\pi}{2 g} \int_{0}^{t}[a(t)]^{2} d t
$$




$$
I_{a, \infty}=I_{a}(\infty)=\frac{\pi}{2 g} \int_{0}^{\infty}[a(t)]^{2} d t
$$

where $a(t)$ is the acceleration time history and $g$ is the acceleration due to gravity

Figure 14a shows the Arias intensities computed as a function of time for the input motion, clay surface, single pile and pile groups for the three different input motions. In Fig. 14a, the Arias intensities of clay surface and pile foundations are increasing with the increase in intensity of the input motion except for the case of clay surface attenuation during the input motion-3. Figure $14 \mathrm{~b}$ shows the response of the free field clay surface and pile foundations in terms of Arias intensity, but the vertical axis is the ratio of Arias intensity to the final value of Arias intensity of the corresponding input motion, i.e., $I_{a}$ $(t) / I_{a, \infty}^{\text {input }}$, called normalised Arias intensity (NAI). During the input motions-1 and 2, the clay surface and pile foundations' NAIs are greater than 1, indicating the amplification of input motions. However, during input motion-3, the NAI is lower than 1 for clay surface
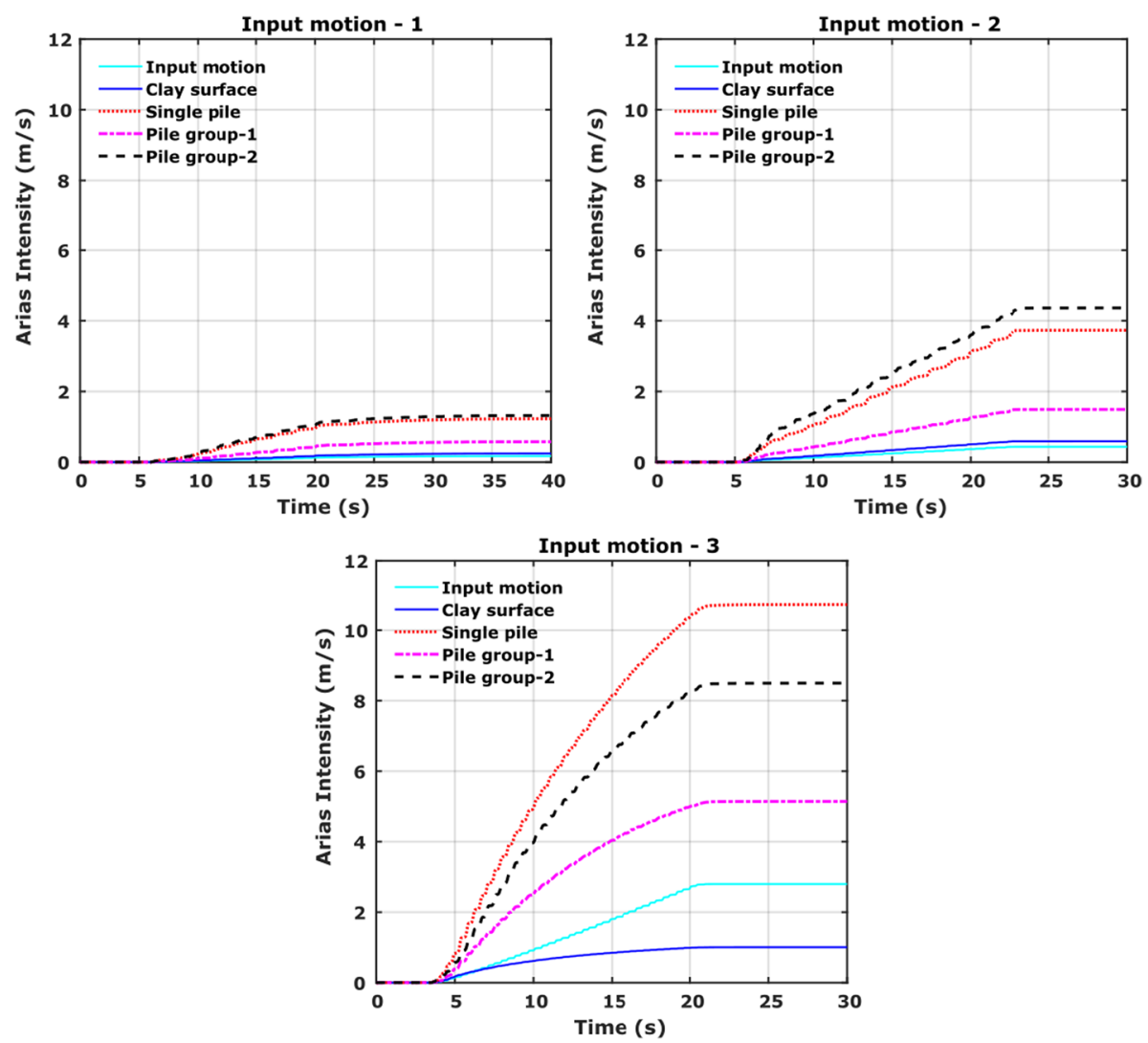

(a)

Fig. 14 Pile foundations' response during the different input motions, a actual response, b normalised response 

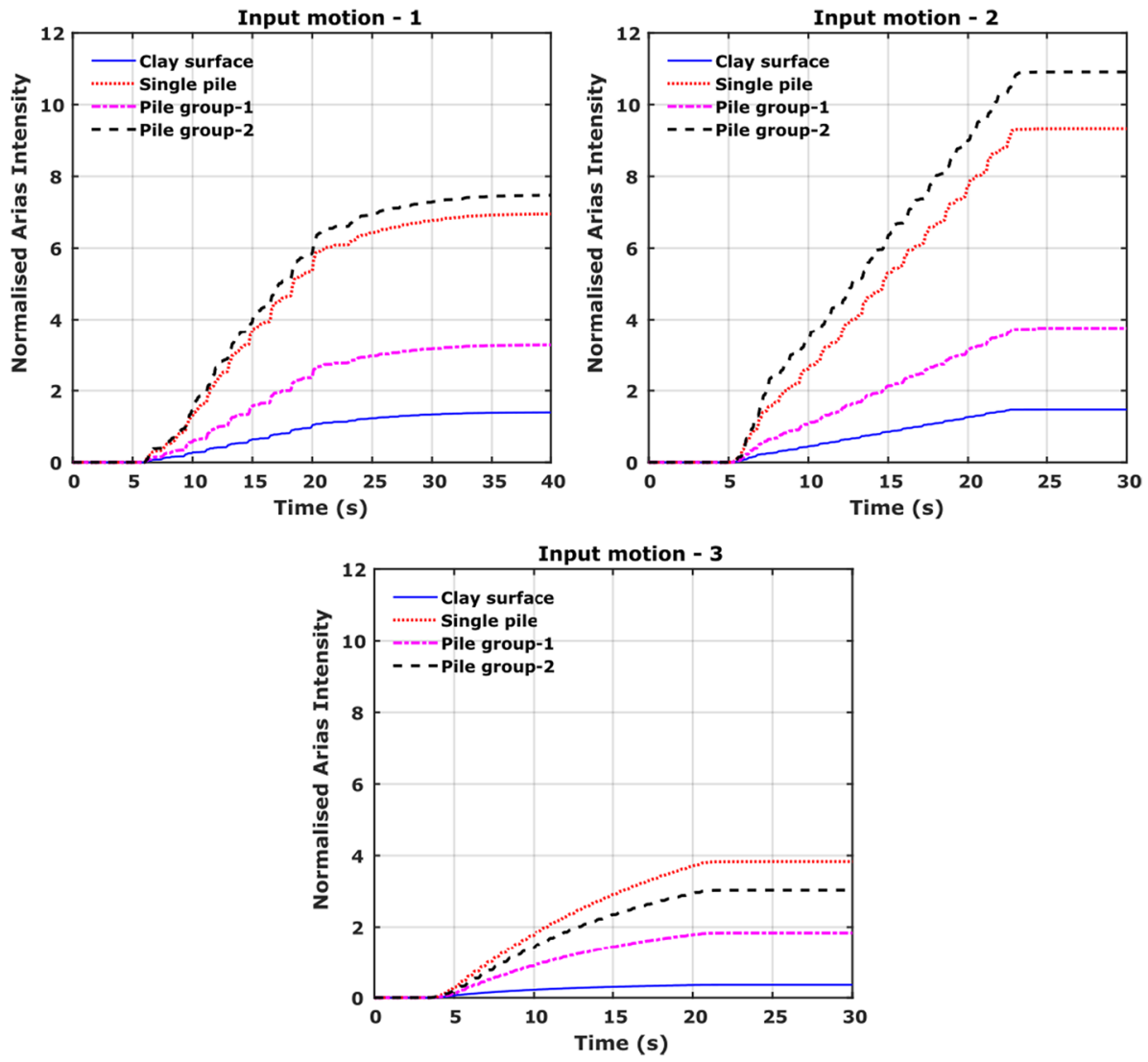

(b)

Fig. 14 (continued)

indicating attenuation of input motion as it propagates through the soft clay, as seen in Figs. 7 and 14a.

The most striking feature observed in Fig. 14b is that the least NAI is observed for the strongest motion, i.e., input motion-3. This is true for single pile as well as both pile groups-1 and 2. The highest NAI is seen during input motion-2 for the single pile and pile group-2. This suggests that amplification can occur for smaller to medium intensity shaking (input motions-1 and 2) but strong attenuation results for stronger intensity shaking (input motion-3). More amplification occurred in input motion-2 than in input motion-1. This suggests that until the shear strength of the clay is reached amplification can occur, but once the input motion generates shear stresses larger than the shear strength of clay, attenuation results. Further in all cases, the single pile behaviour is close to the widely spaced pile group- 2 . The closely spaced pile group- 1 results in smaller NAI's for all the three input motions considered. This suggests that there is strong interaction between the piles in this group owing to their close spacing.

Overall the dynamic response of friction pile foundations during seismic loading greatly depends on the behaviour of clay surrounding them and the intensity of the 
bedrock motion. If there is no yielding of clay during the dynamic loading, then both the free field surface and pile foundations' acceleration response will be amplified relative to the input motion. However, when there is a yielding of clay during strong bedrock motion, the free field surface motion will be attenuated strongly. The behaviour of pile foundations during such attenuated motions depend on the motion received by the pile foundations at their tip levels and the excitation of the surrounding soil. The results presented in this paper show that there will be a strong interaction between the piles and the surrounding soil owing to the differences in their acceleration response.

\section{Conclusions}

A series of centrifuge experiments were carried out to investigate the behaviour of friction pile foundations in soft clay during the earthquakes. A single model pile and two sets of $3 \times 1$ row model pile groups with different pile spacing were embedded into the soft kaolin clay and were subjected to sinusoidal excitations of smaller to stronger intensities in a $50 \mathrm{~g}$ centrifuge test. The following are the major conclusions from this research:

1. The amplification or attenuation of bedrock acceleration as it propagates through the soft clay depends on the intensity of the input motion and strength and stiffness of the clay. The clay will amplify the bedrock motion if the shear stresses generated because of shear wave propagation are less than the shear strength of the clay. If clay yields during the strong excitations, then the attenuation of input motion will result.

2. For smaller intensity input motions, the difference between equivalent linear and nonlinear analyses from DEEPSOIL software is quite small. However, for stronger intensity input motions, the equivalent linear analysis over predicts the site response while nonlinear analysis is able to capture the observed attenuation in the centrifuge test data.

3. During the smaller to medium intensity input motions, both the single pile and pile groups tested show amplification. During stronger intensity input motion, all piles tested show amplification relative to the clay surface motion, which shows marked attenuation.

4. Using the normalised arias intensity (NAI) plots it can be seen that the amplification of the single pile and two pile groups is the least for the strongest input motion, owing to the yielding of clay.

5. The behaviour of the single pile is comparable to the widely spaced pile group for both smaller and stronger intensity input motions. The pile group with closely spaced piles behaved quite different to the single pile, due to the strong interaction between each of the piles.

It must be pointed out that the input motions used in this research are sinusoidal excitations. It would be interesting to investigate the behaviour of single pile and pile groups subjected to more realistic motions in the future.

Acknowledgements The authors would like to thank Prof. Luca de Sanctis and Dr Raffaele Di Laora, the Parthenope University of Naples for their collaboration in this project. The first author would also like to thank the Commonwealth Scholarship Commission (CSC) and Cambridge Trust for their doctoral scholarship. The authors also appreciate the technicians at the Schofield Centre of Cambridge University for their 
assistance during the centrifuge experiments. The authors would also like to thank the anonymous reviewers for their valuable feedback on this article.

\section{Compliance with ethical standards}

Conflict of interest The authors declare that they have no conflict of interest.

Open Access This article is distributed under the terms of the Creative Commons Attribution 4.0 International License (http://creativecommons.org/licenses/by/4.0/), which permits unrestricted use, distribution, and reproduction in any medium, provided you give appropriate credit to the original author(s) and the source, provide a link to the Creative Commons license, and indicate if changes were made.

\section{References}

Agarwal SL (1973) Soil structure interaction of dynamically laterally loaded pile based on discrete element method. In: 5th world conference on earthquake engineering, Rome, pp 1902-1904

Anoyatis G, Di Laora R, Mandolini A, Mylonakis G (2013) Kinematic response of single piles for different boundary conditions: analytical solutions and normalization schemes. Soil Dyn Earthq Eng 44:183-195

Arias A (1970) A measure of earthquake intensity. In: Hansen RJ (ed) Seismic design for nuclear power plants. MIT Press, Cambridge, pp 438-483

Banerjee S (2009) Centrifuge and numerical modelling of soft clay-pile-raft foundations subjected to seismic shaking. PhD dissertation, National University of Singapore

Brennan AJ, Madabhushi SPG (2002) Design and performance of a new deep model container for dynamic centrifuge testing. In: Phillips R, Guo PJ, Popescu R (eds) International conference on physical modelling in geotechnics, Newfoundland, Canada. Balkema, Rotterdam, pp 183-188

Brennan AJ, Thusyanthan NI, Madabhushi SPG (2005) Evaluation of shear modulus and damping in dynamic centrifuge tests. J Geotech Geoenviron Eng 131(12):1488-1498

Darendeli MB (2001) Development of a new family of modulus reduction and material damping curves. PhD dissertation, University of Texas Austin

Durante MG, Di Sarno L, Mylonakis G, Taylor CA, Simonelli AL (2016) Soil-pile-structure interaction: experimental outcomes from shaking table tests. Earthq Eng Struct Dyn 45(7):1041-1061

Fan K, Gazetas G, Kaynia A, Kausal E (1991) Kinematic seismic response of single piles and pile groups. J Geotech Eng (ASCE) 117(12):1860-1879

Finn WD, Gohl WB (1992) Response of model pile groups to strong shaking. In: Piles under dynamic loads, geotechnical special publication no. 34. ASCE, pp 27-55

Garala TK (2016) Dynamic behaviour of pile foundations in soft clay. 1st year PhD report, Department of Engineering, University of Cambridge

Gazetas G (1984) Seismic response of end-bearing single piles. Soil Dyn Earthq Eng 3(2):82-93

Ghosh B, Madabhushi SPG (2002) An efficient tool for measuring shear wave velocity in the centrifuge. In: Phillips R, Guo PJ, Popescu R (eds) International conference on physical modelling in geotechnics, Newfoundland, Canada. Balkema, Rotterdam, pp 119-124

Groholski DR, Hashash YMA, Kim B, Musgrove MI, Harmon JA, Stewart JP (2016) Simplified model for small-strain nonlinearity and strength in 1D seismic site response analysis. J Geotech Geoenviron Eng 142(9):04016042

Hansbo S (1984) Foundations on friction creep piles in soft clays. In: 1st international conference on case histories in geotechnical engineering, Missouri University of Science and Technology, Missouri, pp 913-922

Hashash YMA, Musgrove MI, Harmon JA, Okan I, Groholski DR, Phillips CA, Park D (2017) DEEPSOIL 7.0, user manual. University of Illinois at Urbana-Champaign

Hokmabadi AS (2014) Effect of dynamic soil-pile-structure interaction on seismic response of mid-rise moment resisting frames. PhD dissertation, University of Technology Sydney

Horikoshi K, Randolph MF (1996) Centrifuge modelling of piled raft foundations on clay. Geotechnique 46(4):741-752

Idriss IM (1990) Response of soft soil sites during earthquakes. H Bolton Seed memorial symposium. University of California, Berkeley, pp 273-289

Kramer SL (1996) Geotechnical earthquake engineering. Prentice Hall, Upper Saddle River 
Lau BH (2015) Cyclic behaviour of monopile foundations for offshore wind turbines in clay. PhD dissertation, University of Cambridge

Madabhushi SPG (2014) Centrifuge modelling for civil engineers. CRC Press, Boca Raton

Madabhushi SPG, Schofield AN, Lesley S (1998) A new stored angular momentum (SAM) based earthquake actuator. In: International conference on centrifuge. Balkema, Tokyo, pp 111-116

Madabhushi SPG, Knappett J, Haigh S (2010) Design of pile foundation in liquefiable soils. Imperial College Press, London

Mahmood K, Rehman Z, Farooq K, Memon SA (2016) One dimensional equivalent linear ground response analysis-a case study of collapsed Margalla Tower in Islamabad during 2005 Muzaffarabad Earthquake. J Appl Geophys 130:110-117

Mamoon SM, Banerjee PK (1990) Response of piles and pile groups to travelling $\mathrm{S}_{\mathrm{h}}$ waves. Earthq Eng Struct Dyn 19(4):597-610

Meymand PJ (1998) Shaking table scale model tests of nonlinear soil-pile-superstructure interaction in soft clay. PhD dissertation, University of California, Berkeley

Mizuno H, Iiba M (1992) Dynamic effects of backfill and piles on foundation impedance. In: 10th world conference on earthquake engineering, vol 3, Madrid, pp 1823-1828

Mizuno H, liba M, Kitagawa Y (1984) Shaking table testing of seismic building-pile-two-layered-soil interaction. In: 8th world conference on earthquake engineering, vol 3, San Francisco, pp 649-656

Novak M (1974) Dynamic stiffness and damping of piles. Can Geotech J 11(4):574-598

Phanikanth VS, Choudhury D, Gudheti RR (2011) Equivalent-linear seismic ground response analysis of some typical sites in Mumbai. Geotech Geol Eng 29(6):1109-1126

Puri N, Jain A, Mohanty P, Bhattacharya S (2018) Earthquake response analysis of sites in state of Haryana using DEEPSOIL software. In: 6th international conference on smart computing and communications, vol 125. Procedia Computer Science, Haryana, pp 357-366

Rashidi HR (1994) Centrifuge and theoretical study of the earthquake soil-pile-structure interaction of structures founded on clays. PhD dissertation, University of California, Davis

Robinson RG, Tan TS, Lee FH (2003) A comparative study of suction-induced seepage consolidation versus centrifuge consolidation. Geotech Test J 26(1):92-101

Schofield AN (1980) Cambridge geotechnical centrifuge operations. Geotechnique 30(3):227-268

Sreerama K (1993) Dynamic pile-soil-pile interaction using model tests under simulated earthquakes. PhD dissertation, University of Missouri-Rolla

Tomlinson MJ (1995) Pile design and construction practice. E \& FN Spon, London

Vucetic M, Dobry R (1991) Effect of soil plasticity on cyclic response. J Geotech Eng (ASCE) 117(1):89-117

Wilson D (1998) Dynamic centrifuge tests of pile supported structures in liquefying sand and soft clay. PhD dissertation, University of California, Davis

Zhang L, Goh SH, Yi J (2017) A centrifuge study of the seismic response of pile-raft systems embedded in soft clay. Geotechnique 67(6):479-490

Zhou YG, Chen J, Chen Y, Kutter BL, Zheng B, Wilson DW, Stringer ME, Clukey EC (2017) Centrifuge modelling and numerical analysis on seismic site response of deep offshore clay deposits. Eng Geol 227:54-68 